\title{
Legal Aspects of the Care of Older People in Hong Kong and Nurse's Role in it
}

\author{
Baljit Kaur ${ }^{1,2}$ \\ ${ }^{1}$ Lecturer, Nursing, \\ The Open University of Hong Kong \\ Hong Kong \\ bkaur@ ouhk.edu.hk \\ ${ }^{2}$ The University of Hong Kong \\ baljit@connect.hku.hk
}

\begin{abstract}
Legal system provide different means of protection to older people in Hong Kong in terms of life ending decision making, elder abuse, financial and housing affairs. Nurses often plays an important role in it such as begin an advocator and providing professional views and knowledge for helping the older people to plan their life.
\end{abstract}

Keywords-older people, nurses, legal systems

\section{INTRODUCTION}

Most citizens have few encounters with the legal system during their lives. Perhaps sale of flats, a divorce and perhaps a lawsuit for personal injury are the only events that bring the normal person into contact with lawyers and the law. However, older people need to make plans and decisions that raise important legal questions ${ }^{[1]}$. For instance, what arrangements will be made if illness strikes Who will make decisions on the person's behalf if long-term physical or mental incompetence develops? How does one qualify for government benefits? Problems related to legal aspects will always be encountered by all elders no matter they are receiving treatments in hospital, nursed in an old age home or just living in community. With these problems, older people will usually turn to their family or trusted friends. But these persons may not be able to provide knowledgeable answers or help. Thus, health care professionals, including nurses, maybe the next source consulted for information and advice.

Each country or city has its unique legal system, Hong Kong is no exception. Legal sources in Hong Kong will be briefly introduced while its relevance regarding to the care of older people in Hong Kong will be explored in 4 aspects which are encountered by most elders, including life ending decision making, elder abuse, financial affairs and housing affairs. Moreover, review of current systems and nurse's role will also be discussed in each aspect ${ }^{[2]}$.

\section{LEGAL SOURCE IN HONG KONG}

Hong Kong Laws are basically composed of 4 sources, including the Basic Law, Common Law, Rules of Equity and Statute Law ${ }^{[2]}$.The Basic Law underlines the principle of "one country, two systems" whereby the socialist system and policies shall not be practiced in the HKSAR. It also authorizes Hong Kong to exercise a high degree of autonomy, protects the fundamental rights of citizens and describes the political structure of Hong Kong ${ }^{[4]}$. Common Law and Rules of Equity refers to a system of case precedents, not only the judicial decisions generated within Hong Kong but case law from all jurisdictions throughout the common law world ${ }^{[4]}$. Lastly, Statue Law is the made locally under delegated powers, which the majority of ordinances are passed legislative procedure in the Legislative Council ${ }^{[5]}$. Law concerning about care of the older people will provide legal authority on protecting elders in different aspects.

\section{LIFE ENDING DECISION MAKING}

Although one may experience health problems at any age, health-care decision making is a particularly important concern to the elderly population ${ }^{[5]}$.Very often, they were concerned about death and the steps they can take to control the manner of their health. This may involve issue such as euthanasia, withholding life-sustaining treatment or advance directives ${ }^{[6]}$.

\section{LIFE ENDING DECISION MAKING LEGAL ASPECTS}

\section{IN HONG KONG}

In Hong Kong, although there's no legislation pinpointing this issue, 2 guidelines are available. Firstly, the section on "care of the terminally ill" in the Professional Code and Conduct of the Medical Council of Hong Kong provides a framework for these issues ${ }^{[7]}$, while the Hospital Authority further elaborates with another guideline on Life-sustaining Treatment in the Terminally Ill ${ }^{[8]}$.

Concerning euthanasia, the Medical council of Hong Kong (2009) defined it as "direct intentional killing of a person as part of the medical care being offered" which is illegal and unethical. Elder's request for euthanasia is often a sign of calling help due to uncontrolled physical symptoms, psychological distress or social problem ${ }^{[9]}$.Due to its illegality, nurses need to clearly state that euthanasia is absolutely not an 
option for patient. Problems related to their request should be revealed and solved carefully through communication and discussion with the elder and family.

Concerning life-sustaining treatment, the Hospital Authority (2002) agrees that it is legally acceptable to withhold or withdraw life-sustaining when the treatment is futile and when a mentally competent and properly informed patient refuses the life-sustaining treatment. For futile, it can be viewed as medical treatments that is believed to offer no reasonable hope of improving patient's condition or achieving its purpose ${ }^{[10]}$.However, clear-cut situations of physiologic futility is not common, usually in most clinical situations where futility is considered, it involves a decision-making process for balancing the burdens and benefits towards the patient, trying to build a consensus among the health care team, the patient and the family ${ }^{[8]}$.

For elders who are mentally competent and properly informed, their decisions of withdrawing life-sustaining treatment must be respected. For elder who has lost the capacity to make a decision, despite Hong Kong had no specific legislation on advance directives, the Hospital Authority will operate under common law principles where a valid advance directive of refusing life-sustaining treatment is respected ${ }^{[11]}$.A legally appointed guardian is legally entitled to make decision for patient without a valid advance directive ${ }^{[8]}$.According to the Mental Health Ordinance (Cap 136) of Hong Kong, "a legally appointed guardian" is defined as "a guardian vested with power to consent to treatment" which includes giving and withholding consent for treatment considered to be benefit or futile to the patient respectively ${ }^{[12]}$. If a mentally incapacitated elder has no guardian nor a valid advance directive, the final decision should be a medical decision, based on the best interests of the patient ${ }^{[8]}$. Nevertheless, it is stressed that all decisions should be made through discussion among all parties involved to arrive at a consensus.

\section{REVIEW OF LIFE ENDING DECSION SYSTEM}

Different societies have different approaches in decisions to forgo life-sustaining treatment. In the United States, if there is no valid advance directive, family is the dominant decision maker according to medical information and treatment options provided by the healthcare team ${ }^{[13]}$. While in United Kingdom, family has no authority to make such decision and the final decision rests with the doctor in-charge based on the best interests of the patient ${ }^{[14]}$. In Hong Kong, instead of using a decision authority like other foreign countries, it is the process rather than the dominance of a particular role which determines the decisional outcome ${ }^{[15]}$.

Despite the influence of British sovereignty for over two hundred years, Chinese traditional culture has been shown on the decision system which emphasizes the value of harmony among human relationship. From the Analects stated by Confucius (1978), "Harmony is the most valuable things brought by the ritual practices" and "The exemplary person seeks harmony rather than agreement". These 2 sayings show that harmony has a cardinal importance in Chinese traditional culture. Thus, when making decisions about life ending treatment, besides considering the interest of the incompetent dying elder, views of family and healthcare team are also involved to seek harmonious outcome among related parties. This offers an opportunity to work out, rather than compromise.

There are criticisms of the Hong Kong model concerning life-sustaining treatment about the lack of a clear locus of decision authority since neither the family nor the healthcare team are recognized to be the principal decisionmakers for life and death decisions on behalf of incompetent patients ${ }^{[9]}$.However, humans are not machines when dealing with life-and-death issue, overly formalizing processes of decision-making can force the solution in a disingenuous way. An emphasis on shared decision process allows both physician and family to express and discuss their perspectives ${ }^{[15]}$. It is more appropriate for showing respect to the unique individuality of patients and their different conceptions of what constitutes "good dying" [15].

\section{ROLE OF NURSES ROLE IN LIFE ENDING DECISION SYSTEM}

For elders in hospitals, nurse is the one who spend the most time providing care for them among all other healthcare professionals ${ }^{[16]}$. They mainly deal with end-of-life issue by being an emotional supporter, communicator and comforter ${ }^{[17]}$.

For emotional support, it is essential for elders and their parents which includes being present in bedside, providing comfort and a listening ear. Many patients include elders are struggle to face death ${ }^{[18]}$. They need to make decisions about their life ending treatments despite of suffering from physical illness, side effects of treatments and also psychological stresses ${ }^{[18]}$.Not only patients, study also discovered high levels of anxiety and depression among family members especially induced by a technological hospital environment, such as tubes, wires and alarms of machines ${ }^{[19]}$.Thus, emotional support is essential for both parties. Nurses should also acknowledge their psychological reactions, which may include denial, anger, guilt or blame with empathetic attitude, providing a way for them to express.

Communicator is regarded as an essential role for nurses to provide high-quality and compassionate care for dying elders and their families ${ }^{[21]}$.In some situations, family may request treatments which are unable to produce net benefits to the elder and not considered by the healthcare team. This can occur when they continue to hold unrealistic expectations or incorrect information about the life expectancy and quality of life after conducting life-sustaining treatments ${ }^{[20]}$.Misunderstandings are needed to be clarified through further discussion with good communication skills. Moreover, 
patient and family members' social, cultural and religious background should also be considered to facilitate communication ${ }^{[8]}$.For example, believers of Jehovah have a religious view of refusing any blood transfusion, nurses are responsible to reveal their background and show respect to their uniqueness during discussion to reach consensus effectively.

Comforter usually refers to symptom management. Common symptoms of dying elders may include respiratory distress, nausea and increased respiratory tract secretions ${ }^{[17]}$. Nursing interventions such as suctioning, turning and wound care should be provided to keep them comfortable. Inevitably, pain is the most prevalent symptom associated with these procedures ${ }^{[21]}$.Nurses are responsible to assess the level of pain using different pain scales and provide opioids and sedatives as doctor prescribed. Families should also be told that comfort care would always be offered by nurses despite withholding life-sustaining treatments ${ }^{[8]}$.

\section{ELDER ABUSE}

According to the Social Welfare Department (2006), elder abuse is defined as endangering the welfare or safety of an elder people by committing or omitting any acts. There are six forms of elder abuse, including physical abuse, psychological abuse, neglect, financial abuse, sexual abuse, and abandonment ${ }^{[26]}$.In Hong Kong, elder abuse has been increased from 276 in 2005 to 368 in 2011 which physical abuse is the most common form of abuse, contributing $73.6 \%$ among total cases ${ }^{[22]}$.Abusers are mainly family members such as spouse where female victims are more than male victims ${ }^{[23]}$.

\section{ELDER ABUSE LEGAL ASPECTS IN HONG KONG}

Hong Kong has no specific law pinpointing elder care. According to the Department of Justice (2013), elders are currently protected by different ordinances such as Offences Against the Person Ordinance (Cap. 212), Theft Ordinance (Cap. 210), Domestic and Cohabitation Relationships Violence Ordinance (Cap. 189) and Crimes Ordinance (Cap. 200). Elder abusers will be prosecuted under these ordinances according to the types of abuse they have executed. For instance, abusers committed physical abuse to an elder will be punished under the Offences Against the Person Ordinance while financial and sexual abusers will be charged using the Theft Ordinance and Crimes Ordinance respectively.

\section{SERIOUS UNDERREPORTING OF ELDER ABUSE}

Many elder people prefer tolerating the abuser rather than disclosing the incidents which often leads to underreporting ${ }^{[24]}$.According to 'Informal Essay of Director of Social Welfare Department' (2002), 80 of 110 older people suspected of being abuse refuse to report or receiving any service due to various reasons.
Elder people who are living with family members which are most probably their main care-givers, providing physical, psychological and emotional support for them ${ }^{[25]}$. Based on the legal system in Hong Kong, abusers maybe sentenced into jail which means they need to be separated from family members such as sons or wife ${ }^{[26]}$.Thus, reporting the abusers may result in broken of relationship, absence of support and poorer quality of life, which are all main concerns of elder people ${ }^{[27]}$.Moreover, traditional Chinese culture emphasizes concepts like " every family has its problems and that individual should mind his or her own business" and "we should not hang our bad affairs in the public". Elders may feel ashamed to report that they were abused by their own children ${ }^{[28]}$.Thus, they would tolerate rather than disclosing the incidents. Other than home, institutions such as old aged home or hospital is another common place of elder abuse ${ }^{[29]}$. Elder people usually rely heavily on care provided by caseworkers in these institutions due to different health problems ${ }^{[25]}$.Similar to family abuse, elder people tolerated the abuse since they fear of being abandoned without receiving proper care $^{[27]}$.

\section{REVIEW OF THE LEGAL ASPECTS OF ELDER ABUSE}

In addition to a low report rate of elder abuses, people criticized that the legal system in Hong Kong was not comprehensive enough to protect the elder due to poor reporting system. In Hong Kong, although there are guidelines about the procedure when elder abuse is countered by difference disciplines, there's no mandatory reporting system to report elder abuse cases ${ }^{[29]}$.Unless the life of the elder people is threatened, medical social worker needs to follow the elder's will whether he or she wants to report or not ${ }^{[30]}$.However, from Brashier (2010), health care professionals in United States, including doctors, nurses, social workers and law enforcement personnel are mandated to report elder abuse when suspected case is encountered. Also, other individuals are encouraged to do so. Furthermore, some states in America give employee a private cause of action against anyone who causes an adverse change in his employment status as a result of his report of elder abuse ${ }^{[31]}$.This is especially important for employees of a nursing home to report suspected abuse or provides information to investigating officials, protecting them from employers' retaliation.

\section{ROLES OF NURSESIN LEGAL ASPECTS OF ELDER ABUSE}

When elders are discharged from hospitals, community nurses are among the first professionals to encounter older people in old age home or in community by providing regular visits ${ }^{[32]}$.With a serious underreporting and poor reporting system mentioned before, nurse plays a more important role to protect elders from being abused by being a detector, curer and educator ${ }^{[33]}$. 
For detector, nurses need to notice the occurrence of different indicators of elder abuse, including physical, behavioral and environmental indicators ${ }^{[30]}$. For instance, Brown, Streubert \& Burgess (2009) suggested that elders being physically abused usually have unexplainable bruises, lacerations or even fractures at multiples parts of their body. They may also exhibit unusual behavior such as withdrawal, apprehension and unwilling to receive medical examination. Finding of unusual restraint equipments and deprivation of facilities for contacting the outside world are environmental indicators need to be alerted by nurses. If more than one indicators appear at the same time, nurses need to take notice and be alerted ${ }^{[34]}$.A comprehensive assessment should then also be done on elders' physical, mental, family background and supporting network to consider if further intervention is needed $^{[34,35]}$.

Nurses act as a curer through providing standard and comprehensive care as well as ending the abuse $\left({ }^{[36]}\right.$. Abuse will endanger and impair the elder physically or psychologically ${ }^{[30]}$. For physical aspect, it usually refers to injuries caused by abusers, which nurses can provide standard care to enhance physical recovery ${ }^{[23]}$. While for psychological aspect, nurses can provide psychological support for the elder and the abuser through supportive counseling, especially for those with mental trauma ${ }^{[23]}$.However, as mentioned before, elder usually tolerate the abusers. Nurses in this role have to help the abused elder to exposure the abuse to light rather than tolerating it. Miller (2004) has pinpointed that elder people will be more willing to accept outside help if nurses can build therapeutic relationship with the abused elder. Thus, nurses not just help the elder recover from the abuse, but also help the elders to get back to normal life.

For educator, nurses can provide talks to educate the public about the distinct manifestation, risk factors and consequences of elder abuses, increasing public awareness about the issue ${ }^{[37]}$.Yan \& Kwok (2011) showed that taking care of a dementia elder with cognitive and physical impairments can impose great burdens for caregivers which is a stressor leading to elder abuse. Education is therefore crucial for caregivers of dementia elders who are prompt to burnouts ${ }^{[38]}$. Besides teaching them about the ways of providing suitable care for a dementia elder, nurses should also advise them to notice signs of burnouts and share the caring responsibility with other family members ${ }^{[38,39]}$. As a result, elder can receive standard and appropriate care without being abused.

\section{FINACIAL AFFAIRS}

Working is the most common source of income in life. But for older people, once they are retired, financial problem can be encountered if they haven't got enough savings in the past ${ }^{[1]}$.Even if they want to find a job, it is difficult due to stereotypical preconceptions from most people that ability deteriorates with increasing age ${ }^{[40]}$. To protect the elder, legal aspects need to be involved in providing retirement plans and preventing age discrimination in employments.

\section{FINANCIAL AFFAIRS LEGAL ASPECTS IN HONG KONG}

Concerning about retirement plan, Hong Kong government enacted the Mandatory Provident Fund Schemes Ordinance ("MPFSO") (CAP 485) in August 1995 to provide a formal system of basic retirement protection ${ }^{[41]}$. It offers a framework for the workforce to acquire financial benefits for elders after retirement.

According to The Hong Kong Special Administrative Region Government (2012b), Mandatory Provident Fund System is a forced retirement saving program, covering all employees and self-employed persons who are at least 18 and under 65 years old. Under the MPFSO, the mandatory contribution rate is 10 percent of an employee's relevant income, with the employer and employee each paying 5 percent. An employee earning less than the minimum of relevant income, $\$ 6500$ per month or $\$ 78000$ per year is not required to contribute while the employer must contribute 5 percent of the employee's relevant income. Employers are required to choose at least one scheme for their employees, offering a couple of investment funds with different risk levels for them to select. Employees cannot withdraw his accrued benefits before the retirement age of 65, or ceases employment and attains the age of $60^{[42]}$. Although MPF system does not provide a guarantee on the minimum rate of return of the investment of the scheme assets, there are different kinds of safety mechanisms of protection against malfeasance or illegal conduct by the trustee and its service providers, such as insurance cover, on-going monitoring and compensation fund (Siu, 2002). This ensures the MPF system can accumulate a fund to support elders' life after their retirements.

For age discrimination, it refers to employees who are subject to unfair or different treatment in respect of his or her employment on the ground of age ${ }^{[43]}$.In Hong Kong, the Labour Department (2006) had issued the "Practical Guidelines for Employers on Eliminating age Discrimination in Employment" to avoid age discrimination. However, these guidelines are not backed up by legislation and employers and employment agencies are encouraged to follow on a voluntary basis to the best of their ability ${ }^{[44]}$.

\section{REVIEW OF THE FINANCIAL SYSTEM}

Before the implementation of the Mandatory Provident Fund System in December 2000, only about one-third of the workforce of 3.4 million people, mainly civil servants and professionals, had some form of retirement protection ${ }^{[45]}$.Given the 10 percent contribution rate and retirement age at 65 , there are still many variable factors affecting the accumulated fund after retirement, such as the length of working life, the wage growth and the rate of return on investment ${ }^{[46]}$. Especially for people who are over or nearly 
attain the age of 60 , their working life is too short to accumulate the fund under the MPF system. Thus, this system is not comprehensive enough for protecting all elders in Hong Kong due to its relatively short history of implementation ${ }^{[47]}$.Also, only limited help can be provided for workers whose lifetime earnings were low and for those who were unemployed for a long period of time ${ }^{[46]}$.

While concerning the age discrimination, Hong Kong only had guideline which is quite lagging behind compared with foreign countries like the United States. Since 1967, the Age Discrimination in Employment Act had already enacted in United States to protect applicants and employees 40 years of age and older from age discrimination ${ }^{[48]}$.It was designed to ensure employers use ability instead of age to make working decision, such as hiring, promotion and compensation ${ }^{[49]}$.Thus, this provides a better legal protection for elders in job findings.

\section{ROLE OF NURSES IN FINANCIAL SYSTEM}

Poor financial status can be one of the reasons causing physical and psychological problems. For instance, nutrition or clothing will be inadequate for elders who don't have enough money for buying ${ }^{[50]}$.Worse still, inadequate saving can be a psychological stress for elders, which can be a risk factor of depression ${ }^{[51]}$.According to the World Health Organization (2013), nurses are responsible for the promotion of health which includes physical, mental and social aspects of a person. Financial status is certainly one of the social aspects need to be revealed by community nurses.

For elders who are revealed to have current financial difficulties, referrals to social workers can be done by nurses for applying different social security program, such as the Old Age Allowance (OAA) set up by the Hong Kong Government [55]. It can be divided into normal OAA \& higher OAA, providing $\$ 1090$ cash allowance on a monthly basis. Normal OAA is for elderly persons aged between 65-69 whose income and assets do not exceed the prescribed levels, while higher OAA is for elderly persons aged 70 or above. In addition to OAA, the government has proposed an "Old Age Living Allowance" (OALA) of \$2200 a month to supplement the living expenses of elderly people who need financial support ${ }^{[55]}$.Nevertheless, elders with low education level or various disabilities may not have clear understanding of complicated details about those allowances ${ }^{[56]}$.Thus, besides doing referral, nurses can provide simple information about allowances available, such as eligible criteria, ways of application and uses of those allowances.

\section{HOUSING AFFAIRS}

The home is important to most elderly person, not only because of the memories it contains, but also because the home represents stability in their life ${ }^{[1]}$.Elderly people may feel that as long as they remain at home, they still have control of their life ${ }^{[1]}$.Some individual are fortunate enough to remain at home, and living independently until death. However, many other individual will have physical, mental, or financial problems, requiring them to leave their homes and live elsewhere, including Homes for the Aged, Hostels for the Elderly, Care and Attention Homes for the Elderly and Temporary residential services ${ }^{[57]}$.

\section{HOUSING AFFAIRS LEGAL ASPECTS OF HONG KONG}

For legal concerning housing affairs, it provides protection for both elders who live in at home and residential care home. For those living at home, the Hong Kong Mortgage Corporation Limited (2012) had launched the reverse mortgage program. It operates under the Conveyancing and property ordinance (CAP 219) which allows elders to use self-occupied residential properties as security to borrow from a participating bank ${ }^{[58]}$. Besides receiving monthly payouts over a fixed period, most importantly, elders can continue to stay at their properties in their rest of their life without changing their living environments ${ }^{[58]}$.

While for elders living in residential homes, they are protected by the Residential Care Homes (Elderly Persons) Ordinance (CAP 459) which came into full operation in June $1996{ }^{[60]}$.It ensures all residential homes are operated under the same licence system. Moreover, under section 22, the code of practice for residential homes was set up, listing out the principles, procedures, guidelines and standards of care for the operation ${ }^{[61]}$.Any residential homes which operate without a valid license or break the agreement of any conditions will be liable for conviction, including fine punishment of $\$ 10,000$ for each day during the offence continues and imprisonment for not exceeding 2 years.

The legal system in Hong Kong is similar to other foreign countries which can protect elders who either staying at their properties or living in residential care homes. Old people always want to stay in their old homes if possible due to memories and stability. However, after retirement, they may encounter financial problem due to shortage of income. For those who want to increase their monthly income without selling their old flats, reverse mortgage provides a perfect way for them to achieve the purpose.

Elders living in residential home may require certain kinds of special care due to physical or mental impairment. It is crucial for them to receive a standard level of care from workers ${ }^{[31]}$.Especially for some private old age homes, since no registered or enrolled nurses are available, there's no grantee on the quality of services provides. Health care workers are main care providers which are non-professionals. The Residential Care Homes (Elderly Persons) Ordinance and the code of practice provide legal guidelines for owners and workers in order to provide a standard level of care. Also, the punishment system can also discourage any violation of 
practice, ensuring the quality of care provide by all residential care homes ${ }^{[57]}$.

\section{ROLES OF NURSES IN HOUSINGAFFAIRS}

Poor living environment or sudden change of living environment may lead to psychological stress for older people ${ }^{[65]}$.Similar to financial affairs, housing affairs also belongs to one of the social aspects need to be revealed by nurses. Nurse's roles in this aspect include assessor, coordinator and educator.

For assessor, the best housing option depends on 2 factors, including the activities of daily living (ADL) and the instrumental activities of daily living (IADL). ADL refers to some basic self care tasks such as toileting, grooming and bathing while IADL refers to complex skills needed to successfully live independently such as managing finances, handling transportation and shopping. Nurses are responsible for assessing these 2 factors in order to determine whether the elder is able to live independently or not, thus choosing the best housing option for them.

Nurse also acts as a coordinator between elders and different disciplines. For elders who are revealed to have problem about housing affairs, nurses should do referrals to social workers and apply suitable housing program for them ${ }^{[69]}$.According to the Hong Kong Housing Authority (2012), priorities will be given to elders for applying public housing estates with different priority schemes available for elders with different needs. For instance, the Harmonious Families Priority Scheme was set up for elders who want to live with younger families while the Elderly Persons Priority Scheme is for elders who want to live with another elder, mainly their husband or wife. With these priorities, elders hopefully can live in an environment with satisfactory and acceptable facilities.

Lastly, for educator, nurses can provide education on self-care training and different community resources for elders before they are discharged from hospitals. This is especially important for those who are hospitalized for a long time or need to cope with new physical impairment since their ADL and knowing about community resources maybe seriously impaired.With education provided, not only elders' decision making in daily living can be enhanced, they will also know what community resources they can access if any problems about housing affairs are encountered.

\section{CONCLUSION}

With no doubts, legal system can provide different protection and benefits for different care of older people, including the life ending decision making, elder abuse, financial and housing affairs. However, it still needs the co-operation from different disciplines which nurse is one of them. Nevertheless, it was shown that legal aspects in Hong Kong are not comprehensive enough to protect all elders, especially in elder abuse and financial affairs. Thus, nurse plays a more important role to help elders to have better planning for their life.

\section{REFERENCES}

[1] Frolik, L. A., \& Kaplan, R. L. (2010). Elder Law in a nut shell. United States of America: West publishing.

[2] Department of Health. (2008). End of Life Care Strategy - Promoting High Quality Care for All Adults at the End of Life. London: Department of Health.

[3] Community Legal Information Centre. (2010). Sources of Law in Hong Kong. Retrieved on February 10, 2013, from http://www.clic.org.hk/en/topics/hkLegalSystem/sourcesOfLawInHong Kong/.

[4] Smith, P. W. (1998). An Introduction to the Hong Kong Legal System. Hong Kong: Oxford University Press.

[5] Jegan, J. J. (1990). The aged client and the law. New York: Columbia University Press.

[6] Fung, A. T., Lam, L. W., \& Lui, V. C. (2010). Could hypothetical scenarios enhance understanding on decision for life-sustaining treatment in non-demented Chinese older persons?. Aging \& Mental Health, 14(8), 994-999.

[7] Medical council of Hong Kong. (2009). Code of professional conduct. Retrieved on February 10, 2013, from http://www.mchk.org.hk/Code_of_Professional_Conduct_2009.pdf.

[8] Hong Kong Housing Authority. (2012). Public housing for senior citizens. Retrieved on February 10, 2013, from http://www.housingauthority.gov.hk/en/public-housing/meeting-specialneeds/senior-citizens/index.html

[9] Chong, A. M., \& Fok, S. (2005). Attitudes towards euthanasia in Hong Kong - a comparison between physicians and the general public. Death Studies, 29(1), 29-54.

[10] Canadian nurses association. (2001). Futility presents many challenges for nurses. Retrieved on February 10, 2013, from http://www2.cnaaiic.ca/cna/documents/pdf/publications/Ethics_Pract_Futility_challenges _May_2001_e.pdf.

[11] Food and Health Bureau. (2009). Introduction of the Concept of Advance Directives in Hong Kong. Retrieved on February 10, 2013, from

http://www.gov.hk/en/residents/government/publication/consultation/do cs/2010/AdvanceDirectives.pdf.

[12] Hong Kong Special Administrative Region. (2007). Mental Health Ordinance (CAP.136). Hong Kong: The Director of Government Logistics.

[13] Black, B., Fogarty, L., Phillips, H., Finucane, T., Loreck, D., Baker, A., \& ... Rabins, P. (2009). Surrogate decision makers' understanding of dementia patients' prior wishes for end-of-life care. Journal Of Aging \& Health, 21(4), 627-650.

[14] Williams, N., Dunford, C., Knowles, A., \& Warner, J. (2007). Public attitudes to life-sustaining treatments and euthanasia in dementia. International Journal Of Geriatric Psychiatry, 22(12), 1229-1234.

[15] Tse, C., \& Tao, J. (2004). Strategic Ambiguities in the Process of Consent: Role of the Family in Decisions to Forgo Life-Sustaining Treatment for Incompetent Elderly Patients. Journal Of Medicine \& Philosophy, 29(2), 207-223.

[16] McLellan, A. (2008). Nurses have a key role to play in tackling elder abuse. From http://www.nursingtimes.net/nurses-have-a-key-role-toplay-in-tackling-elder-abuse/1907538.article.

[17] Efstathiou N., \& Clifford C. (2011). The critical care nurse's role in End-of-life care: issues and challenges. British Association of Critical Care Nurses, 16(3), 116-123.

[18] Bach, V., Ploeg, J., \& Black, M. (2009). Nursing roles in end-of-life decision making in critical care settings. Western Journal of Nursing Research, 31, 496-512. 
[19] Simpson S. (1997). Reconnecting: the experiences of nurses caring for hopelessly ill patients in intensive care. Intensive and Critical Care Nursing, 13, 189-197.

[20] Stedeford, A. (1984). Facing death: patients, families and professionals. Oxford: Heinemann Medical.

[21] Puntillo, K. A., Morris, A. B., Thompson, C. L., Stanik-Hutt, J., White, C. A., \& Wild, L. R. (2004). Pain behaviors observed during six common procedures: results from Thunder Project II. Critical Care Medicine, 32, 421-427.

[22] Social Welfare Department. (2012b). Statistics on newly reported elder abuse cases. From http://www.swd.gov.hk/en/index/site_pubsvc/page_family/sub_listofser v/id_serabuseelder/

[23] Yan, E., \& Tang, C. (2001). Prevalence and psychological impact of Chinese elder abuse. Journal Of Interpersonal Violence, 16(11), 11581174.

[24] Chan, A. C. M., Cheng, S. T., \& Li, C. (2007). Protective law for older persons in Hong Kong. Asian Journal of Gerontology \& Geriatrics, 2(3), 143-152.

[25] Chau, W. Y. E., \& Tang, S. K. C. (2004). Elder abuse by caregivers: A study of prevalence and risk factors in Hong Kong Chinese families. Journal of Family Violence, 19(5), 269-277.

[26] Department of Justice. (2013). Bilingual Laws Information System. From http://www.justice.gov/jmd/ls/legislative_histories/legislativehistories.html.

[27] Sijuwade, P. O. (1995). Cross-cultural perspectives on elder abuse as a family dilemma. Social behavioral and personality, 23(3), 247-252.

[28] Lachs, M. S., Williams, C., O’Brien, S., Hurst, L., and Horwitz, R. (1997). Risk factors for reported elder abuse and neglect: A nineyear observational cohort study. The Gerontologist, 37, 469-474.

[29] Kapp, M. B. (2010). Legal aspects of elder care. Sudbury: Jones and Bartlett Publishers.

[30] Social Welfare Department. (2006). Procedural Guidelines for Handling Elder Abuse Cases. Hong Kong: Hong Kong Government Printer.

[31] Brashier, R. C. (2010). Mastering Elder Law. Durham: Carolina Academic Press.

[32] Winterstein, T. (2012). Nurses' Experiences of the Encounter With Elder Neglect. Journal of Nursing Scholarship, 44, 55-62.

[33] Miller, A. C. (2004). Elder Abuse: The Nurse's Perspective. Clinical Gerontologist, 28(1), 105-133.

[34] Brown, K., Streubert, G., \& Burgess, A. (2004). Effectively detect and manage elder abuse. The Nurse Practitioner, 29(8), 22.

[35] Sandmoe, A., \& Kirkevold, M. (2011). Nurses' clinical assessments of older clients who are suspected victims of abuse: an exploratory study in community care in Norway. Journal Of Clinical Nursing, 20(1/2), 94102.

[36] Irish Nurses Organization. (2004). Guidelines for Nurses in the Understanding and Prevention of Elder Abuse. Ireland: Irish Nurse Organization.

[37] Peri, K., Fanslow, J., Hand, J., \& Parsons, J. (2009). Keeping older people safe by preventing elder abuse and neglect. Social Policy Journal of New Zealand, 35, 159-172.

[38] Choi, N. G., \& Mayer, J. (2000). Elder abuse, neglect and exploitation: risk factors and prevention strategies. J Gerontol Social Work, 33, 5-25.

[39] Lee, M. (2008). Caregiver stress and elder abuse among Korean family caregivers of older adults with disabilities. Journal Of Family Violence, 23, 707-712.

[40] Roscigno, V. J., Mong, S., Byron, R., \& Tester, G. (2007). Age Discrimination, Social Closure and Employment. Social Forces, 86(1), 313-334.

[41] Hong Kong Special Administrative Region Government. (2012b). Hong Kong: the facts. Mandatory Provident Fund. Hong Kong: the Information Services Department.
[42] Mandatory Provident Fund Scheme Authority. (2010). Learn more about MPF regulations. Hong Kong: Mandatory Provident Fund Scheme Authority.

[43] Chou, R. (2012). Discrimination against Older Workers : Current Knowledge, Future Research Directions and Implications for Social Work. Indian Journal Of Gerontology, 26(1), 25-49.

[44] Labour Department. (2006). Practical Guidelines for Employers on Eliminating age Discrimination in Employment. Hong Kong: The Government of the Hong Kong Special Administrative Region.

[45] Chu, P. K., \& McKenzie, M. (2008). A Study on Stock-Selection and Market-Timing Performance: Evidence from Hong Kong Mandatory Provident Funds. Review of Pacific Basin Financial Markets and Policies, 11(4), 617-649.

[46] Siu, A. (2002). Hong Kong Mandatory Provident Fund. Cato Journal, 22(2), 317-332.

[47] Chan, C. K. (2003). Protecting the ageing poor or strengthening the market economy: the case of the Hong Kong Mandatory Provident Fund. International Journal of Social Welfare, 12, 123-131.

[48] Holliday, C. P. (2010). The Age Discrimination in Employment Act of 1967: Issues Litigated at the Supreme Court Level. Florida Bar Journal, 84(2), 20-25.

[49] Rothenberg, J. Z., \& Gardner, D. S. (2011). Protecting Older Workers: The Failure of the Age Discrimination in Employment Act of 1967. Journal Of Sociology \& Social Welfare, 38(1), 9-30.

[50]

[51] Skinner, M. A., Zautra, A. J., \& Reich, J. W. (2004). Financial Stress Predictors and the Emotional and Physical Health of Chronic Pain Patients. Cognitive Therapy \& Research, 28(5), 695-713.

[52] Social Welfare Department. (2012a). Old age living allowance: Helping the elderly in need within our financial means. Hong Kong: The Director of Government Logistics.

[53] Boyle, P. A., Lei, Y., Wilson, R. S., Gamble, K., Buchman, A. S., \& Bennett, D. A. (2012). Poor Decision Making Is a Consequence of Cognitive Decline among Older Persons without Alzheimer's Disease or Mild Cognitive Impairment. Plos ONE, 7(8), 1-5.

[54] Gallo, N. R. (2009). Elder Law. Delmar: Cengage Learning.

[55] The Hong Kong Mortgage Corporation Limited. (2011). Reverse Mortgage Programme Information Pack. Hong Kong: The Hong Kong Mortgage Corporation Limited.

[56] The Hong Kong Mortgage Corporation Limited. (2012). Reverse Mortgage Programme. From http://www.hkmc.com.hk/eng/pcrm/ourbusiness/rm.html.

[57] Hong Kong Special Administrative Region. (2012a). Residential Care Homes (Elderly Persons) Ordinance (CAP.136). Hong Kong: The Director of Government Logistics.

[58] Borbasi, S., Emmanuel, E., Farrelly, B., \& Ashcroft, J. (2010). A Nurse Practitioner initiated model of service delivery in caring for people with dementia. Contemporary Nurse, 36, 49-60.

Baljit Kaur had obtained her Bachelor of Science (Nursing) (Hons) degree from Oxford Brooks University. She had obtained two master degrees. One of the master degree is in Master of Science (Nursing) from Oxford Brooks University and the other master degree is from The University of Hong Kong in Master of Social Science (Gerontology). She is now currently a $\mathbf{P h D}$ candidate in The University of Hong Kong. Her major interest in research is transcultural nursing, nursing education, ethical and legal nursing, simulation education, primary health care and gerontology. 